\title{
Self-Determination in a Physical Exercise Program to Promote Healthy Habits in Sedentary Adults: a Mixed Methods Approach
}

\author{
Sílvia Puigarnau*, Oleguer Camerino, Marta Castañer and Raúl Hileno \\ INEFC (National Institute of Physical Education of Catalonia), IRBLLEIDA (Lleida Institute for Biomedical Research Dr. Pifarré Foundation), University \\ of Lleida, Lleida, Spain
}

Submission: October 28, 2017; Published: December 13, 2017

*Corresponding author: Sílvia Puigarnau, National Institute of Physical Education (INEFC)-University of Lleida.

Email: silviapuigarnau@gmail.com, spuigarnau@inefc.es

\begin{abstract}
This study aimed to compare the perceptions and opinions of sedentary adults regarding two physical exercise programs, one in which an instructor applied motivational strategies based on self-determination theory with the aim of encouraging healthy habits, and another in which no guidance of this kind was offered. We examined the influence that the instructor's intervention had on the perceived benefits of the program, the ability to overcome barriers to exercise, users' views regarding the instructor's role, and social relatedness in the group. Participants were 56 sedentary adults ( 8 men and 48 women) aged between 18 and 60 years $(M=36.02 ; S D=10.15)$ who enrolled in a six-month program of moderate exercise, comprising three 50-minute sessions per week. Two groups were formed: a guided group in which a fitness instructor applied motivational strategies with the aim of promoting self-determination, and a non-guided group that received no such input alongside their exercise routine. A mixed methods approach was used to analyze data from questionnaires, interviews, and the diaries that participants kept throughout the program. The results showed that participants in the guided group reported: (a) more positive views regarding the benefits of the program, (b) greater satisfaction of basic psychological needs, (c) fewer barriers to regular exercise, and (d) the experience of positive relationships in the sessions.
\end{abstract}

Keywords: Self-determination theory; Intrinsic motivation; Physical exercise program; Fitness instructor

Abbreviations: SDT: Self-Determination Theory; PNSE: Psychological Need Satisfaction in Exercise; COM: Perceived Competence; AUTO: Perceived Autonomy; REL: Perceived Relatedness; INTE: Integrated Regulation; INTRO: Introjected Regulation; AMO: On A motivation; INTRI: Intrinsic; GRID: Grup De Recerca E Innovació En Dissenys

\section{Introduction}

Although moderate to vigorous physical activity is recognized to be beneficial for personal wellbeing [1] a large proportion of the population remains sedentary and unable to engage in regular exercise on their own [2].

According to self-determination theory (SDT), motivational behavior is mediated by two factors: (a) satisfaction of basic psychological needs, such as autonomy, competence, and the development of social relationships, and (b) an increase in self-determined motivation [3]. The ability to maintain and enjoy physical activity depends on whether a person's decisionmaking mechanisms lead him or her to adopt a favorable attitude towards regular exercise [4]. An increased awareness of its benefits will favor more self-determined regulation, and hence higher levels of physical activity and satisfaction in everyday life [5-8]. Conversely, a person who lacks motivation will soon give up on an exercise regime [9-10] .
Research with adults who engage in physical exercise $[9,11]$ shows that an increase in intrinsic motivation, the presence of an instructor who encourages autonomy [2], and attention to social relatedness can lead to greater involvement and commitment.

In persons unaccustomed to exercise, the social aspect is particularly relevant when they are starting out, as well as in helping them to make a regular commitment $(12,13)$.

One question that arises from this is whether or not fitness instructors can prevent people from losing motivation and giving up on physical exercise. In this context, studies suggest that effective intervention strategies [14,15], an instructional style based on positive encouragement $[11,16]$, and good communication on the part of instructors $[17,18]$ are aspects that can boost people's confidence and participation in physical exercise programs.

The aim of the present study was to compare the perceptions and opinions of a sample of sedentary adults who were enrolled 
in two physical exercise programs. In one program a fitness instructor applied motivational strategies based on selfdetermination theory to encourage the development of healthy habits among group members, whereas the other program involved no such additional input alongside the exercise routine. Comparison of the two groups revealed that participants had different perceptions and opinions regarding their motivation and the extent to which their basic psychological needs were satisfied.

\section{Material and Methods}

\section{Participants}

Participants were 56 sedentary adults ( 8 men and 48 women) aged between 18 and 60 years $(M=36.02 ; S D=10.15)$. They all expressed an interest in taking up regular physical exercise and volunteered to participate in the study. The sample was divided into two groups: the guided group comprised 35 adults aged between 18 and 56 years $(M=38.83 ; S D=9.48)$, who in addition to their exercise program received input from a fitness instructor in the form of motivational strategies designed to promote selfdetermination; the non-guided group consisted of 21 adults aged between 21 and 60 years $(M=31.86 ; S D=9.88)$, who received no professional input of this kind alongside their exercise program. In order to be eligible for inclusion, participants had to have no health problem or be under no prescribed drug treatment for which moderate or vigorous exercise would be contraindicated.

\section{Measures}

The instruments used are shown in Figure 1.

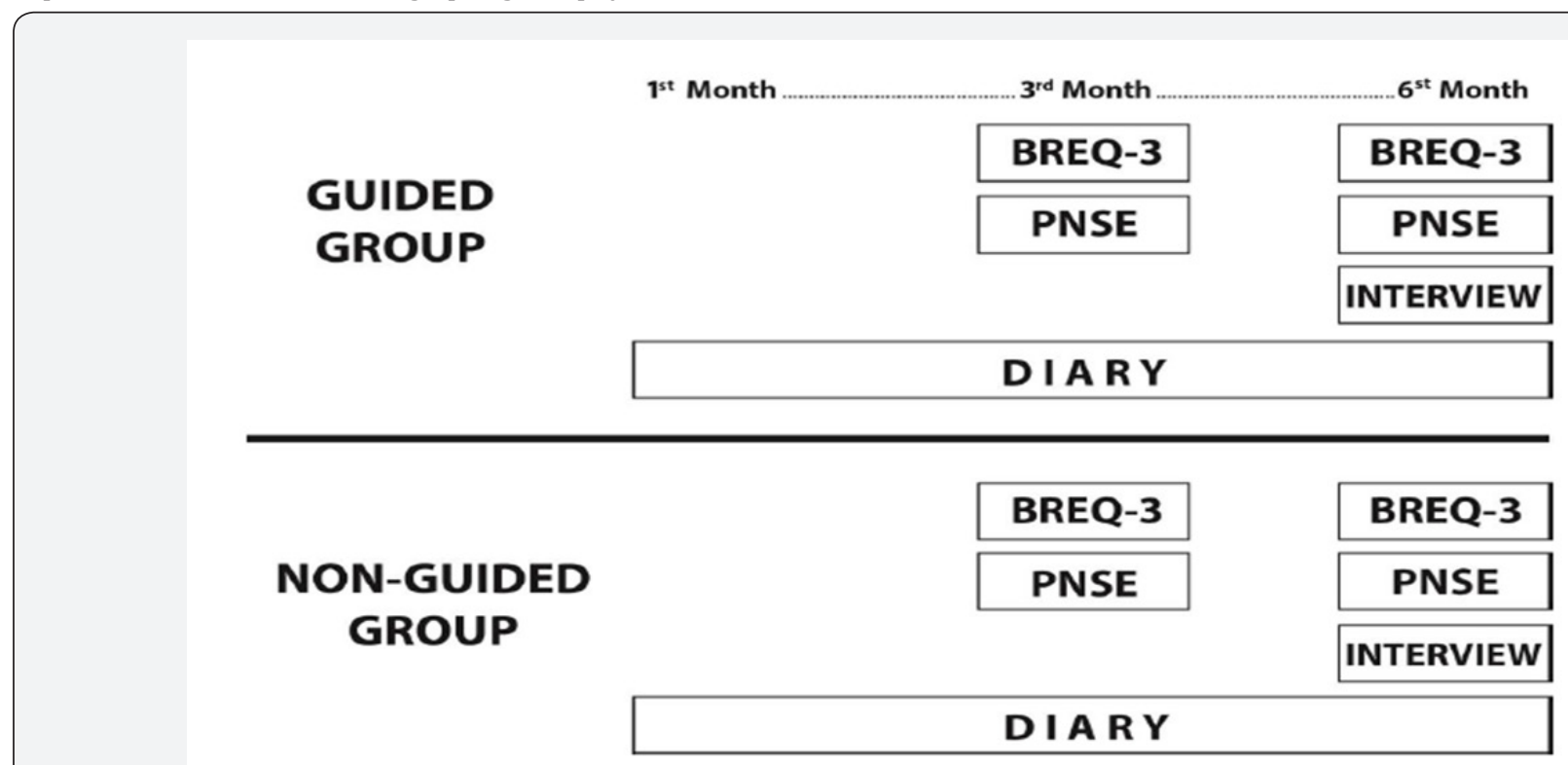

Figure 1: Outline of the assessment schedule.

The Psychological Need Satisfaction in Exercise (PNSE) Scale [19]. This instrument comprises 18 items that reflect the three indicators of the degree to which these needs are satisfied: perceived competence (COM), perceived autonomy (AUTO), and perceived relatedness (REL) (an example of a COM item would be "I am capable of doing challenging exercises"). Responses are given using a 6-point Likert scale, anchored by $1=$ strongly disagree and $6=$ strongly agree.

Behavioral Regulation in Exercise Questionnaire-3 (BREQ3) $[19,20]$. This 23 -item questionnaire operationalizes exercise motivation across a self-determination continuum and includes subscales that assess intrinsic, integrated, identified, interjected, and external regulation (an example item for the latter would be "I exercise because other people say I should"), as well as amotivation. Responses are given using a 5-point Likert scale, anchored by $0=$ Not true for me, and $4=$ Very true for me.

Personal exercise diary (Figure 1) [21]. At the end of each session, participants in both groups filled in a personal exercise diary containing questions about their motivation, difficulties encountered, social relatedness, and perceptions before and during the session (e.g., "Did you find today's session difficult?").

Semi-structured interview [22]. This comprised six questions asking about the person's previous experience of exercise/sport, the overcoming of barriers, the perceived benefits of exercise, and the outcomes achieved. The content of the interview was validated by a panel of experts, who confirmed that the questions were comprehensible, relevant, and important. A representative subsample of eight participants (four from each of the two groups) who had regularly attended the first four months of the exercise program was interviewed for the present study. These interviews were recorded and subsequently transcribed, a procedure for which the interviewees signed informed consent.

\section{Procedure}

The nature of the study was explained to participants, both verbally and in writing, and it was made clear to them that their anonymity would be maintained throughout the research. Once their informed consent had been obtained we then administered 
to all participants the Processes of Change Questionnaire [23] in order to confirm that the degree of preparedness to take up physical exercise was balanced across the two groups, since both would be required to complete 150 minutes of moderate exercise per week. For both the guided and non-guided groups the program ran over a period of six months and involved three weekly sessions lasting 50 minutes each, all of which took place in the same fitness center.

The questionnaires (Figure 1) were administered at two different points in time (Assessment 1 and Assessment 2), and the interviews of the eight selected participants were conducted at the fitness center during the final month of the program. The personal exercise diaries were completed at the end of each session.

\section{Statistical Analysis}

The Kolmogorov-Smirnov and Shapiro-Wilks tests were used to test the normality of the data derived from the questionnaires (BREQ-3 and PNSE), with the results obtained by each group being compared by means of parametric (Student's T) and non-parametric tests (Wilcoxon) for independent samples. The association between the different variables was then examined by calculating Pearson and Spearman correlation coefficients, thus enabling us to examine the relationship between the indicators for the sample as a whole. For all tests the level of statistical significance was set at $P<.05$, with analyses being conducted using IBM SPSS Statistics v20.0 (IBM Corp, Armonk, NY, USA).

Finally, and in order to provide a global interpretation of results, we analyzed the data using a mixed-methods triangulation design $[17,24]$. This enabled us to compare the quantitative data from questionnaires with the qualitative information provided by the exercise diaries and the interview transcriptions, the content of which was subjected to content analysis by means of the Atlas-ti 6.2 software (Scientific Software Development GmbH, Berlin).

\section{Results}

\section{Comparison of Means}

Table 1 shows that in the first administration of the PNSE, participants in the non-guided group scored higher than those in the guided group on perceived competence (COM) and perceived autonomy (AUTO), with the latter difference reaching statistical significance $(P<.05)$. Although the non-guided group continued to score higher on perceived autonomy in the second assessment, the difference was no longer significant, and what is more, the guided group now scored higher on perceived competence. At both assessment points, guided participants scored higher than their non-guided counterparts on perceived relatedness (REL). These results illustrate a positive trend in the guided group, whereas scores in the non-guided group on all three PNSE subscales were lower at the second assessment point.

Table 1. Descriptive results (mean and standard deviation) for the BREQ-3 and PNSE in the guided and non-guided groups at the two assessment points

\begin{tabular}{|c|c|c|c|c|c|c|c|c|c|c|c|}
\hline \multicolumn{5}{|c|}{ Assessment 1} & \multicolumn{7}{|c|}{ Assessment 2} \\
\hline \multicolumn{3}{|c|}{$\begin{array}{c}\text { Non-guided } \\
\text { group } \\
\end{array}$} & \multicolumn{2}{|c|}{$\begin{array}{l}\text { Guided } \\
\text { group }\end{array}$} & \multicolumn{3}{|c|}{$\begin{array}{l}\text { Guided } \\
\text { group }\end{array}$} & \multicolumn{4}{|c|}{$\begin{array}{l}\text { Guided } \\
\text { group }\end{array}$} \\
\hline Measure & Sub-scale & $\mathbf{x}$ & SD & $\mathbf{x}$ & SD & $\mathbf{P}$ & $\mathbf{x}$ & SD & $\mathbf{x}$ & SD & $\mathbf{P}$ \\
\hline \multirow[t]{3}{*}{ PNSE } & $\mathrm{COM}$ & 4.51 & 0.86 & 4.21 & 0.95 & .26 & 4.25 & 1.13 & 4.35 & 1.05 & .75 \\
\hline & AUTO & 4.23 & 1.08 & 3.44 & 0.92 & $.05^{*}$ & 4.06 & 1.11 & 3.70 & 1.19 & .29 \\
\hline & REL & 3.74 & 0.68 & 4.05 & 0.87 & .16 & 3.52 & 0.98 & 3.87 & 0.94 & .26 \\
\hline \multirow[t]{6}{*}{ BREQ-3 } & INTRI & 3.11 & 0.78 & 3.11 & 0.59 & .63 & 2.99 & 0.89 & 3.37 & 0.61 & .11 \\
\hline & INTE & 2.13 & 0.95 & 2.04 & 0.97 & .72 & 2.17 & 1.15 & 2.33 & 0.84 & .68 \\
\hline & IDEN & 3.25 & 0.51 & 3.34 & 0.55 & .47 & 3.17 & 0.82 & 3.43 & 0.54 & .30 \\
\hline & INTRO & 1.76 & 0.95 & 1.36 & 0.84 & .10 & 1.96 & 1.06 & 1.47 & 0.86 & .06 \\
\hline & EXTER & 0.37 & 0.61 & 0.49 & 0.76 & .44 & 0.49 & 0.43 & 0.53 & 0.73 & .51 \\
\hline & AMO & 0.46 & 0.54 & 0.40 & 0.51 & .68 & 0.56 & 0.79 & 0.26 & 0.47 & .13 \\
\hline
\end{tabular}

Note. $p \leq .05^{*}$. For the PNSE: COM = perceived competence, AUTO = perceived autonomy, REL = perceived relatedness. For the BREQ-3: INTRI = intrinsic regulation, INTE = integrated regulation, IDEN = identified regulation, INTRO = introjected regulation, EXTER $=$ external regulation, $\mathrm{AMO}=$ amotivation. 
Differences between the two groups were less marked on the BREQ-3 (Table 1). In the first assessment, the non-guided group scored higher on integrated regulation (INTE) and introjected regulation (INTRO), as well as, unsurprisingly, on amotivation (AMO). However, none of these differences reached statistical significance. As with the PNSE, the results for the second BREQ3 assessment showed a favorable trend in the guided group, the only exception being scores on introjected regulation, which remained higher in the non-guided group. Notably, the difference between the two groups in the level of a motivation was greater at the second assessment, the score having increased among non-guided participants and decreased among their guided counterparts.

Table 2. Correlations between the results obtained from the BREQ-3 and PNSE.

\begin{tabular}{|c|c|c|c|c|c|}
\hline \multicolumn{6}{|c|}{ BREQ-3 } \\
\hline Variables & INTRI & INTE & IDEN & INTRO & EXTER \\
\hline INTE & $.402^{* *}$ & & & & \\
\hline IDEN & $.303^{* *}$ & $.306^{* *}$ & & & \\
\hline INTRO & -.152 & .102 & .112 & & \\
\hline EXTER & -.140 & $.318^{* *}$ & -.158 & $.422^{* *}$ & \\
\hline AMO & $-.365^{* *}$ & -.190 & $-.218^{*}$ & .185 & $.237^{*}$ \\
\hline \multicolumn{6}{|c|}{ PNSE } \\
\hline \multicolumn{2}{|c|}{ Variables } & \multicolumn{2}{|c|}{ COM } & \multicolumn{2}{|c|}{ AUTO } \\
\hline \multicolumn{2}{|c|}{ AUTO } & \multicolumn{2}{|c|}{$.325^{* *}$} & & \\
\hline \multicolumn{2}{|c|}{ REL } & \multicolumn{2}{|c|}{$-.234^{*}$} & \multicolumn{2}{|c|}{.168} \\
\hline
\end{tabular}

Note. $p \leq .05^{*} ; p \leq .005^{* *}$. For the PNSE: COM = perceived competence, AUTO = perceived autonomy, REL = perceived relatedness. For the BREQ-3: INTRI = intrinsic regulation, INTE = integrated regulation, IDEN = identified regulation, INTRO = introjected regulation, EXTER = external regulation, $\mathrm{AMO}=$ amotivation.

\section{Correlations}

The correlation analysis (Table 2) of scores obtained on the PNSE in the sample as a whole (guided and non-guided groups) revealed significant and positive associations between several variables. In what follows we focus specifically on those correlations of most relevance in relation to the results of the subsequent qualitative analysis.

A strongly significant and positive association was observed between perceived competence (COM) and perceived autonomy (AUTO). Perceived relatedness (REL) showed a less strongly significant and negative correlation with perceived competence, and no significant association with perceived autonomy, suggesting that social relatedness is a less important aspect in this context.

Table 2 also shows the results of the correlation analysis of scores obtained on the BREQ-3 in the sample as a whole. Both intrinsic (INTRI) and integrated regulation (INTE) showed a significant positive correlation with identified regulation (IDEN) and a negative association with a motivation (AMO); this negative association was significant in the case of intrinsic regulation.

These results suggest that social relations were important when first engaging in the exercise program, but that they became less so once these adults had acquired a greater degree of autonomy through regular participation and experience of the benefits of exercise.

\section{Content Analysis}

The comparison of questionnaire results with the content analysis of the participants' diaries and the interviews is structured according to the four main areas examined: motivation to exercise, barriers to physical exercise, effect of the social context/relationships, and perceptions regarding the instructor.

\section{(a) Motivation to exercise}

The comments made as the exercise program progressed indicated that participants in the guided group felt increasingly motivated, whereas their non-guided counterparts felt less so. This reflects the trends observed in PNSE scores, as well as in the results for intrinsic and identified regulation on the BREQ3 (Table 1). Nonetheless, participants in both groups continued to show a commitment to the program. The number and letters that appear at the end of each example statement refer to the participants' codes.

"The commitment I've made is really important for me... maybe it would be good to have the same obligation when the six months are up." 
Non-guided group_1AC

"I come because I want to take it seriously, I've made a commitment and I don't want to let people down. I wouldn't forgive myself if I did that."

Guided group_2CG.

The setting and the "social climate" were important factors with respect to consolidating relationships in the guided group and in terms of the non-guided participants seeking companions to make the activity more enjoyable. It is worth noting, however, that the comments made did not coincide with the results of the PNSE, where both groups showed a decrease in perceived relatedness (REL) scores between the two assessments (Table 1).

"I really enjoy the group.... I look forward to it as one of the highlights of my week."

Guided group_8MC

"If I hadn't gone to the fitness class I'd have felt really bad. So what I did was ring a friend and she came with me."

Non-guided group_19NS.

Participants in the guided group were clear about the perceived benefits of the exercise program, stating that they felt better both physically and psychologically. These results coincide with the increase in scores observed on the perceived competence (COM) subscale of the PNSE, as well as in the indicators of more self-determined regulation on the BREQ-3 (Table 1).

"Being in the group meant that I felt happy on the days we had the class. I went to work feeling happier".

Guided group_3EG.

My body feels great, and I have a real sense of wellbeing at the end of the session.

\section{(b) Barriers to physical exercise}

Laziness, tiredness, negative mood, and the lack of a companion were common barriers reported by participants in the non-guided group. The obstacles faced by their counterparts in the guided group were, by contrast, more likely to be external in nature (e.g. work or study commitments, family obligations, or injuries). These comments are consistent with the fact that amotivation scores on the PNSE decreased over time in the guided group but increased among non-guided participants (Table 1).

"I always arrive late because of work...and that makes me feel really nervous at the start."
"This weather we're having makes me feel really tired and means I don't really fancy going to the gym when I could... I prefer to have a nap."

Non-guided group_18NC.

\section{(c) Effect of the group}

Exercise companions invariably acted as a stimulus, and identification with the group made the activity more fun and encouraged some individuals to seek out others with whom to practice their new exercise habits. Those participants in the nonguided group who occasionally signed up for other activities offered by the fitness center obtained benefits similar to those reported by the guided group.

"I love being part of the group and feeling, just by looking at people's faces, that we're all suffering together."

Non-guided group_1AC.

"I have a great time in the group, and I look forward to it from the moment I get up. I really don't mind getting up so early because I know that I'm going to be having one of the best times of my week."

Guided group_8MC.

The observed decrease in perceived relatedness (REL) scores on the PNSE could be due to certain points of conflict in the group (Table 1).

"When you do things with other people you have to adapt to their pace... and sometimes I have to take a deep breath because it can irritate me."

Non-guided group_LLB.

\section{d) Participants' views regarding the instructor's role}

The participants wanted to be constantly corrected, to be given clear instructions, and for the sessions to be flexible, in the sense of there being room for their own suggestions and initiative. The presence of an instructor who was helpful and who inspired confidence through good communication and the creative use of interventions led to greater competence, autonomy, and self-determination in relation to physical exercise among group participants.

"The most important thing is that you feel you can trust the instructor, so that you're relaxed in the session and want to go back. Almost all the instructors have inspired confidence and that's been really important for me in terms of carrying on going."

Guided group_4EF.

Some comments, however, serve as a reminder that professionals in this context need to work hard to ensure the quality of their interventions and to prevent users from feeling frustrated. 
"We didn't always understand what he meant, or he'd tell us what to do at the start but then we'd forget and the class would lose its way."

Guided group_1BC.

\section{Discussions and Conclusion}

The results of this study show that participants in the guided group had an increasingly positive view of the program's benefits, this being a key factor in creating healthy exercise habits. We also found that barriers to exercise were more difficult to overcome among participants in the non-guided group, who lacked the external motivation that would derive from identification with the group and the dynamic input of a professional instructor. Both these findings are consistent with previous studies that have examined the strategies used in programs that aim to promote exercise adherence $[2,25,26]$.

Social contact and being part of a group was the most important aspect cited by participants in relation to their attending scheduled fitness classes. Lavigne et al. (2011) [27] similarly noted that interpersonal relationships among group members encouraged persistence in sport, adding that the quality of these relationships was crucial to the development of a sense of wellbeing and the subsequent awareness of the benefits associated with physical exercise [28].

Also of relevance in this context is the study by Lynch (2003) [29], which found that a climate that promotes feelings of security and which supports autonomy can produce a sense of emotional reliance and supportive interpersonal relationships, leading in turn to wellbeing within the group. For their part Sánchez-Oliva et al. (2012) [30], claim that an increased sense of acceptance and the possibility of closer ties with others is a positive predictor of intrinsic motivation. In our view, this could account for the positive functioning of our guided group throughout the program.

The motivational strategies used by the instructor and the group climate are two key aspects in the process of generating autonomy and adherence in relation to exercise. Indeed, the professional's social skills and the establishment of a good working relationship with group members lay the foundations for more self-determined motivation and the incorporation of physical exercise into everyday life. Non-guided programs may achieve positive outcomes with experienced users, but such results are less likely with individuals who, unaccustomed to regular physical activity, need to move from a state of a motivation towards introjected or intrinsic motivation.

This shift towards intrinsic motivation and increased autonomy has been described in longitudinal studies such as those by Kinnafick et al. (2014) [8] and Fortier et al. (2012) [6]. In line with this literature, we believe that the motivational strategies used by the instructor in our guided group helped the participants to achieve a sense of autonomy, commitment, and security, as well as the capacity to overcome barriers to exercise. Outcomes of a similar kind were reported by Edmunds et al. (2008) [31], who found higher attendance rates and the adoption of healthy exercise habits among participants in an SDT-based exercise program, as compared with controls. The women involved in the program also reported an increase in selfdetermined regulation, perceived autonomy, and relatedness with the group. Puente and Anshel (2010) [14] also highlight how effective intervention by instructors is required to produce lasting effects on people's exercise habits, not only in terms of increasing the frequency of activity but also of enhancing a person's sense of enjoyment, autonomy, competence, and relatedness.

Borges-Silva et al. (2015) [2] that one of the key factors in improving attendance at fitness classes is the sense of commitment that the instructor can instill in participants. This is certainly consistent with some of our results, such as the higher attendance rates and reported levels of commitment in the guided group, due to the instructor's input based on SDT. Indeed, the fact that attendance rates were considerably higher in the guided as opposed to the non-guided group suggests that the instructor played a key role in maintaining participants' commitment to the program. This sense of commitment, which our results suggest was also linked to the program itself and the dynamics of the group, helped participants to keep up their attendance and to avoid falling foul of the barriers cited by some participants in their diaries and interviews (e.g., lack of motivation, tiredness, insecurity, and work or family commitments).

These findings highlight the need for fitness centers to ensure the availability of skilled instructors, who in their approach should aim to promote autonomy and increase motivation among users. A strategy of this kind can help those people who are unaccustomed to physical exercise to move towards a more internalized motivation to exercise and, therefore, to make physical activity a regular part of their lives.

\section{Acknowledgment}

\section{Grants, Funding, or Financial Support}

We gratefully acknowledge the support of INEFC (National Institute of Physical Education of Catalonia) and two Spanish government projects (Ministerio de Economía y Competitividad): a) La actividad física y el deporte como potenciadores del estilo de vida saludable: Evaluación del comportamiento deportivo desde metodologías no intrusivas [Grant number DEP2015-66069-P]; b) Avances metodológicos y tecnológicos en el estudio observacional del comportamiento deportivo [PSI2015-71947-REDP]; and the support of the Generalitat de Catalunya Research Group, GRUP DE RECERCA E INNOVACIÓ EN DISSENYS (GRID). Tecnología i aplicació multimedia i digital als dissenys observacionals [Grant number 2014 SGR 971].

\section{References}

1. Johansson M, Hartig T, Staats H (2011) Psychological benefits of walking: Moderation by company and outdoor environment. Appl Psychol Health 


\section{Psychology and Behavioral Science International Journal}

Well Being 3(3): 261-280.

2. Borges Silva F, Prieto Vaello A, Alias A, Moreno Murcia JA (2015) Predicción del motivo salud en el ejercicio físico en centros de fitness [Predicting the health motivation behind physical exercise in fitness centers]. Ricyde 11(40): 163-172.

3. Deci EL, Ryan RM (2000) The "what" and "why" of goal pursuits: Human needs and the self determination of behaviour. Psychol Inq 11(4): 227 268.

4. Moreno JA, González Cutre D, Cervelló E (2008) Motivation and health in sport and exercise: Differences according to smoking and alcohol consumption. Int J Clin Hlth Psyc 8: 483-494.

5. Deci EL, Ryan RM (2008) Facilitating optimal motivation and psychological well-being across life's domains. Can Psychol, Plenum Press, New York, USA, 49: 14-23.

6. Fortier MS, Duda JL, Guerin E, Teixeira PJ (2012) Exercise, physical activity, and self-determination theory: A systematic review. Int J Behav Nutr Phys Act 9: 78.

7. Teixeira PJ, Carraça EV, Markland DA, Silva MN, Ryan RM (2012) Exercise, physical activity, and self-determination theory: A systematic review. Int J Behav Nutr Phys Act 9: 78.

8. Kinnafick FE, Thogersen-Ntoumani C, Duda JL, Y Taylor I (2014) Sources of autonomy support, subjective vitality and physical activity behavior associated with participation in a lunchtime walking intervention for physically inactive adults. Psychol Sport Exerc 15(2): 190-197.

9. Garcia Calvo T, Cervelló E, Jiménez R, Iglesias D, Moreno Murcia J A (2010) Using self-determination theory to explain sport persistence and dropout in adolescent athletes. Span J Psychol 13(2): 677-684.

10. Rodgers WM, Hall CR, Duncan LR, Pearson E, Milne MI (2010) Becoming a regular exerciser: Examining change in behavioural regulations among exercise initiates. Psychol Sport Exerc 11(5): 378-386.

11. Tessier D, Sarrazin P, Ntoumanis N (2008) The effects of an experimental programme to support students autonomy on the overt behaviours of physical education teachers. Euro J Psychol Educ 23: 239-253.

12. Huberty JL, Rasdell L, Sidman C, Meendering J, Shultz B (2013) Explaining Long-Term Exercise Adherence in Women Who Complete a Structured Exercise Program. Research Quarterly for Exercise and Sport 79(3): 374-384

13. Ng JY, Ntoumanis N, Thogersen Ntoumani C, Stott K, Hindle L (2013) Predicting psychological needs and well-being of individuals engaging in weight management the role of important others. Appl Psychol Health Well Being 5(3): 291-310.

14. Puente R, Anshel MH (2010) Exercisers perceptions of their fitness instructors interacting style perceived competence and autonomy as a function of self-determined regulation to exercise enjoyment affect and exercise frequency. Scand J Psychol 51: 38-45.

15. Petitemberte I, Gama de Matos D, Leitao JC, Cid L, Moutao J (2015) Self-determination and Physical Exercise Adherence in the Contexts of Fitness Academies and Personal Training. J Hum Kinet 46: 241-249.

16. Franco S, Simões V, Castañer M, Rodrigues J, Anguera MT (2013) La conducta de los instructores de Fitness: triangulación entre la percepción de los practicantes auto-percepción de los instructores y conducta observada [The behavior of fitness instructors: Triangulation between user perceptions the self-perceptions of instructors and observed behavior]. Rev Psico Deporte 22(2): 321-329.

17. Camerino O, Castañer M, Anguera MT (2012) Mixed Methods Research in the Movement Sciences: Cases in Sport Physical Education and Dance 20(2): 277-282

18. Castañer M, Camerino O, Anguera MT, Jonsson GK (2013) Kinesics and proxemics communication of expert and novice PE teachers. Qual Quant 47(4): 1813-1829.

19. Wilson PM, Rogers WT, Rodgers WM, Wild TC (2006) The Psychological Need Satisfaction in Exercise Scale. J Sport Exerc Psychol 28(3): 231 251.

20. Markland D, Tobin V (2004) A modification of the Behavioral Regulation in Exercise Questionnaire to include an assessment of amotivation. Journal of Sport and Exercise Psychology 26(2): 191-196.

21. Zabalza MA (2008) Diarios de clase: UN instrumento de investigación y desarrollo profesional [Class diaries: An instrument for research and professional development]. Madrid, Spain.

22. Beltrán VJ, Devís J, Peiró C, Brown D (2012) When Physical Activity Participation Promotes Inactivity: Negative Experiences of Spanish Adolescents in Physical Education and Sport. Youth Soc 44: 3-27.

23. Prochaska JO, Diclemente CC, Norcross JC (1992) In search of how people change Applications to addictive behaviors. American Psychologist 47(9): 1102-1114.

24. Anguera MT, Camerino O, Castañer M, Sánchez Algarra P (2014) Mixed methods en la investigación de la actividad física y el deporte. Rev Psico Deporte 23: 123-130.

25. Leyton M, Jiménez R, Naranjo J, Castillo M, Morenas J (2013) Aplicación de un programa motivacional para promocionar la actividad física en adultos y mayores archivos de medicina del reporte [Application of a motivational program to promote physical activity among adults and elders]. Arch Med Dep 30: 25-33.

26. Silva MN, Markland DA, Minderico CS, Vieira PN, Castro MM, et al. (2008) A randomized controlled trial to evaluate self-determination theory for exercise adherence and weight control: Rationale and intervention description. BMC Public Health 8: 234-247.

27. Lavigne GL, Vallerand RJ, Crevier Braud L (2011) The fundamental need to belong: on the distinction between growth and deficit-reduction orientations. Pers Soc Psychol Bull 37(9): 1185-1201.

28. Leo FM, Sánchez Miguel PA, Sánchez-Oliva D, Amado D, García Calvo $\mathrm{T}$ (2014) Analysis of cohesion and collective efficacy profiles for the performance of soccer players. J Hum Kinet 39: 221-229.

29. Lynch MF (2013) Attachment autonomy and emotional reliance: A multilevel model. J Couns Dev 91(3): 301-312.

30. Sánchez Oliva D, Leo FM, Sánchez-Miguel PA, Amado Alonso D, García Calvo T (2012) Antecedentes motivacionales de los comportamientos prosociales y antisociales en el contexto deportivo [Motivational antecedents of prosocial and antisocial behaviors in the sport context] Rev Int Med Cienc Ac 12 46: 253-270.

31. Edmunds J, Ntoumanis N, Duda JL (2008) Testing a self-determination theory based teaching style in the exercise domain. Eur J Soc Psychol 38: 375-388. 
This work is licensed under Creative Commons Attribution 4.0 License

DOI: 10.19080/PBSIJ.2017.07.555714
Your next submission with Juniper Publishers will reach you the below assets

- Quality Editorial service

- Swift Peer Review

- Reprints availability

- E-prints Service

- Manuscript Podcast for convenient understanding

- Global attainment for your research

- Manuscript accessibility in different formats

( Pdf, E-pub, Full Text, Audio)

- Unceasing customer service

Track the below URL for one-step submission https://juniperpublishers.com/online-submission.php 